\title{
Determination of inorganic phosphorus in serum: Evaluation of three methods applied to the Technicon RA-1000 analyzer
}

\begin{abstract}
L. Rubino, V. Catapano and G. Guerra
Clinical Chemistry Laboratory, 'Borselli' Hospital (USL 31), 44012 Bondeno, Ferrara, Italy

We have evaluated three analytical methods for determining inorganic phosphorus in serum applied to the Technicon RA-1000 analyzer: a fully enzymatic colorimetric method based on the specific system purine nucleoside phosphorylase/xanthine oxidase coupled to an indicator colorimetric reaction similar to the Trinder reaction; a chemical method involving the direct $U V$ measurement of the phosphomolybdate complex; and a chemical method with reduction of the phosphomolybdate complex to molybdenum blue. Experiments were performed to assess within-run and between-day precision, linearity, interference and correlation. The best performance characteristics were shown by the enzymatic colorimetric method and the phosphomolybdate UV method.
\end{abstract}

\section{Introduction}

Phosphorus and phosphorylated compounds are largely involved in the main biochemical process, that is bone, carbohydrate, lipid, nucleic acids and energy metabolism. Inorganic phosphorus is the fraction commonly determined in the clinical laboratory and the clinical significance of the measurement of inorganic phosphorus in serum and urine is widely recognized $[1,2]$.

Various analytical techniques have been employed for determining inorganic phosphorus in serum, but the most widely used in the routine work is photometry. Many chemical methods, based on ultraviolet or colorimetric measurements, have been described, however, the continuous proposal of new methods attests a certain dissatisfaction for those available. Enzymatic methods have been described based on UV measurement [3-6] and on colorimetry [7]. Recently, an enzymatic colorimetric method has been made available in a kit format and has gained wide acceptance for its performance characteristics and convenience [8-10].

In the work described in this paper we compared this enzymatic colorimetric method with a chemical method based on the direct UV measurement, and a colorimetric method based on the chemical reduction, all applied to a Technicon RA-1000 analyzer.

\section{Materials and methods}

We applied the following methods to a Technicon RA-1000 random-access analyzer (Technicon Instruments Corp., Tarrytown, N.Y. 10591, USA), carrying out all assays at $37^{\circ} \mathrm{C}$ and calibrating the instrument before linearity, precision and correlation experiments with an aqueous standard at $1.29 \mathrm{mmol} / \mathrm{l}$ of inorganic phosphorus (Chemetron Chimica SpA, Milan, Italy).

\section{Enzymatic colorimetric method}

Inorganic phosphates react first with inosine, in the presence of purine nucleoside phosphorylase (EC 2.4.2.1), to form ribose-1-phosphate and hypoxanthine. The latter is then oxidised by xanthine oxidase (EG 1.1.3.22) to hydrogen peroxide and xanthine, which is in turn oxidised to uric acid with further production of hydrogen peroxide. The liberated hydrogen peroxide reacts, in the presence of peroxidase (EC 1.11.1.7), with the chromogen system 4-aminophenazone/ $N$-ethyl- $N$ (3-methylphenyl)- $N^{\prime}$-acetylethylenediamine with the formation of a red-purple chromogen quinonimine which has an absorption peak at $550 \mathrm{~nm}$ [8-10].

The reagent kit used was from Miles Italiana SpA, Divisione Diagnostici, Cavenago Brianza, Italy. Reagents were reconstituted as per manufacturer's' instructions and a single working solution was prepared. The instrument settings were as follows:

$\begin{array}{lc}\text { GHEM \# } & \\ \text { NAME } & 11 \mathrm{I} . \mathrm{PH} \\ \text { TYPE } & 2 \\ \text { \& SMP VOL } & 7 \\ \text { FILTER POS } & 5 \mathrm{WL} 550 \\ \text { DELAY } & 500 \\ \text { \% RGT VOL } & 70 \\ \text { UNITS } & 4 \mathrm{mmol} / 1 \\ \text { UNIT FAC } & 1 \cdot 0000 \\ \text { DEGIMAL PT } & 1 \\ \text { RBL LOW } & 0 \cdot 000 \\ \text { RBL HI } & 0 \cdot 300 \\ \text { RANGE LOW } & 0 \\ \text { RANGE HI } & 4 \cdot 84 \\ \text { CAL FACTOR } & \ldots \ldots \\ \text { STD VAL } & 1 \cdot 29 \\ \text { NORMAL LOW } & 0 \cdot 80 \\ \text { NORMAL HI } & 1 \cdot 55 \\ \text { SLOPE } & 1 \cdot 000 \\ \text { INTERGEPT } & 0 \cdot 0000 \\ \text { EP LIM } & 0 \cdot 0100 \\ & \\ U V \text { method } & \\ \text { Un } & \end{array}$

Unreduced phosphomolybdate complex, resulting from the reaction of inorganic phosphates with molybdate ions in acid medium, is determined at $340 \mathrm{~nm} \mathrm{[11].} \mathrm{The}$ reagent kit used was from Ghemetron Chimica $\mathrm{SpA}$, Milan, Italy. The instrument settings were as follows: 


\begin{tabular}{|c|c|c|c|c|c|c|}
\hline & \multicolumn{3}{|c|}{ Within-run $(n=15$, each $)$} & \multicolumn{3}{|c|}{ Between-day $(n=15$, each $)$} \\
\hline & $\begin{array}{l}\text { Enzymatic } \\
\text { colorimetric } \\
\text { method }\end{array}$ & $\begin{array}{l}\text { UV } \\
\text { method }\end{array}$ & $\begin{array}{l}\text { Molybdenum } \\
\text { blue method }\end{array}$ & $\begin{array}{l}\text { Enzymatic } \\
\text { colorimetric } \\
\text { method }\end{array}$ & $\begin{array}{l}\text { UV } \\
\text { method }\end{array}$ & $\begin{array}{c}\text { Molybdenum } \\
\text { blue method }\end{array}$ \\
\hline \multicolumn{7}{|l|}{ Control Serum A } \\
\hline True (assigned) value, $\mathrm{mmol} / \mathrm{l}$ & $1 \cdot 00$ & $1 \cdot 00$ & $1 \cdot 00$ & $1 \cdot 00$ & $1 \cdot 00$ & $1 \cdot 00$ \\
\hline Value obtained: & & & & & & \\
\hline $\operatorname{Mean}(\bar{x}), \mathrm{mmol} / \mathrm{l}$ & $1 \cdot 01$ & $1 \cdot 02$ & $1 \cdot 06$ & 0.99 & $0 \cdot 98$ & $1 \cdot 04$ \\
\hline Standard deviation (SD), $\mathrm{mmol} / \mathrm{l}$ & $0 \cdot 003$ & $0 \cdot 013$ & $0 \cdot 016$ & $0 \cdot 009$ & $0 \cdot 019$ & $0 \cdot 016$ \\
\hline Coefficient of variation (CV), \% & $0 \cdot 30$ & $1 \cdot 27$ & $1 \cdot 51$ & $0 \cdot 99$ & $1 \cdot 94$ & $1 \cdot 54$ \\
\hline Coefficient of precision $^{1}(\mathrm{CP}), \%$ & $99 \cdot 70$ & $98 \cdot 73$ & $98 \cdot 49$ & $99 \cdot 01$ & $98 \cdot 06$ & $98 \cdot 46$ \\
\hline Coefficient of accuracy ${ }^{2}$ (CAc), $\%$ & $99 \cdot 00$ & $98 \cdot 00$ & $94 \cdot 00$ & $99 \cdot 00$ & $98 \cdot 00$ & $96 \cdot 00$ \\
\hline Coefficient of analysis ${ }^{3}$ (CA), $\%$ & $98 \cdot 96$ & $97 \cdot 63$ & $93 \cdot 82$ & $98 \cdot 59$ & $97 \cdot 21$ & $95 \cdot 71$ \\
\hline \multicolumn{7}{|l|}{ Control Serum B } \\
\hline True (assigned) value, $\mathrm{mmol} / \mathrm{l}$ & $2 \cdot 20$ & $2 \cdot 20$ & $2 \cdot 20$ & $2 \cdot 20$ & $2 \cdot 20$ & $2 \cdot 20$ \\
\hline \multicolumn{7}{|l|}{ Obtained value: } \\
\hline Mean $(\bar{x}), \mathrm{mmol} / \mathrm{l}$ & $2 \cdot 14$ & $2 \cdot 12$ & $2 \cdot 02$ & $2 \cdot 12$ & $2 \cdot 10$ & $2 \cdot 01$ \\
\hline Standard deviation (SD), $\mathrm{mmol} / \mathrm{l}$ & $0 \cdot 010$ & $0 \cdot 010$ & $0 \cdot 010$ & $0 \cdot 039$ & $0 \cdot 032$ & $0 \cdot 048$ \\
\hline Coefficient of variation (GV), \% & $0 \cdot 47$ & $0 \cdot 47$ & $0 \cdot 50$ & $1 \cdot 84$ & $1 \cdot 52$ & $2 \cdot 39$ \\
\hline Coefficient of precision ${ }^{1},(\mathrm{CP}), \%$ & $99 \cdot 53$ & $99 \cdot 53$ & $99 \cdot 50$ & $98 \cdot 16$ & $98 \cdot 48$ & $97 \cdot 61$ \\
\hline Coefficient of accuracy ${ }^{2},(\mathrm{CAc}), \%$ & $97 \cdot 27$ & $96 \cdot 36$ & $91 \cdot 82$ & $96 \cdot 36$ & $95 \cdot 46$ & $91 \cdot 36$ \\
\hline Coefficient of analysis ${ }^{3},(\mathrm{CA}), \%$ & $97 \cdot 23$ & $98 \cdot 08$ & $91 \cdot 81$ & $95 \cdot 92$ & $95 \cdot 21$ & $91 \cdot 04$ \\
\hline
\end{tabular}

${ }^{1} \mathrm{CP}=100-\mathrm{CV}$.

$2 \mathrm{CAc}=100-\mathrm{CB}$, where $\mathrm{CB}$ is the coefficient of bias defined as $[($ assigned value $-\bar{x}) /$ assigned value $] \times 100$.

${ }^{3} \mathrm{CA}=100-R$, where $R$ is calculated as $\sqrt{(\mathrm{CV})^{2}+(\mathrm{CB})^{2}}$.

Table 2. Linearity

\begin{tabular}{|c|c|c|c|c|c|c|c|}
\hline & \multirow{3}{*}{$\begin{array}{c}\text { Standard } \\
\text { inorganic } \\
\text { phosphorus } \\
\text { mmol/l }\end{array}$} & \multicolumn{5}{|c|}{ Inorganic phosphorus found } & \\
\hline & & \multicolumn{2}{|c|}{$\begin{array}{c}\text { Enzymatic } \\
\text { colorimetric } \\
\text { method }\end{array}$} & \multicolumn{2}{|c|}{ UV method } & \multicolumn{2}{|c|}{ Molybdenum blue } \\
\hline & & $\mathrm{mmol} / \mathrm{l}$ & $\%$ & $\mathrm{mmol} / \mathrm{l}$ & $\%$ & $\mathrm{mmol} / \mathrm{l}$ & $\%$ \\
\hline & $0 \cdot 40$ & 0.43 & $107 \cdot 5$ & $0 \cdot 39$ & $97 \cdot 5$ & $0 \cdot 33$ & $82 \cdot 5$ \\
\hline & $0 \cdot 80$ & $0 \cdot 83$ & $103 \cdot 8$ & 0.75 & $93 \cdot 8$ & $0 \cdot 70$ & $87 \cdot 5$ \\
\hline & $1 \cdot 61$ & 1.65 & $102 \cdot 5$ & $1 \cdot 55$ & $96 \cdot 3$ & $1 \cdot 48$ & $91 \cdot 9$ \\
\hline & $2 \cdot 42$ & $2 \cdot 43$ & $100 \cdot 4$ & $2 \cdot 34$ & $96 \cdot 7$ & $2 \cdot 26$ & $93 \cdot 4$ \\
\hline & $3 \cdot 23$ & $3 \cdot 18$ & $98 \cdot 4$ & $3 \cdot 11$ & $96 \cdot 3$ & $3 \cdot 12$ & $96 \cdot 6$ \\
\hline & $4 \cdot 04$ & $4 \cdot 14$ & $102 \cdot 5$ & $4 \cdot 01$ & $99 \cdot 2$ & $4 \cdot 01$ & $99 \cdot 2$ \\
\hline & $4 \cdot 84$ & $4 \cdot 81$ & $99 \cdot 4$ & $4 \cdot 76$ & $98 \cdot 3$ & $5 \cdot 21$ & $107 \cdot 6$ \\
\hline & $6 \cdot 46$ & $6 \cdot 07$ & $94 \cdot 0$ & $6 \cdot 27$ & $97 \cdot 0$ & $6 \cdot 26$ & $96 \cdot 9$ \\
\hline CHEM \# & & & & $\mathrm{NO}$ & IAL LOW & $0 \cdot 80$ & \\
\hline NAME & 11 I.PH & & & NO & IAL HI & $1 \cdot 55$ & \\
\hline TYPE & 2 & & & SLC & & 1.000 & \\
\hline$\&$ SMP VOL & 10 & & & $\mathrm{IN}^{\prime}$ & CEPT & $0 \cdot 0000$ & \\
\hline FILTER POS & $1 \mathrm{WL} 34 \mathrm{C}$ & & & $\mathrm{EP}$ & & $0 \cdot 0100$ & \\
\hline DELAY & 100 & & & & & & \\
\hline$\%$ RGT VOL & 70 & & & Mo & enum blue me & hod & \\
\hline UNITS & $4 \mathrm{mmol} / 1$ & & & Pho & omolybdat & complex & educed to molybdenum \\
\hline UNIT FAC & $1 \cdot 0000$ & & & blu & $\operatorname{iron}(\mathrm{II}) \mathrm{su}$ & phate [12] & he reagent kit used from \\
\hline DECIMAL PT & 1 & & & $\mathrm{Wa}$ & Chemicals & $\mathrm{GmbH}, \mathrm{N}$ & ss, FR Germany. The \\
\hline RBL LOW & $0 \cdot 000$ & & & inst & nent setting & were as fo & WS: \\
\hline RBL HI & $0 \cdot 275$ & & & & & & \\
\hline RANGE LOW & 0 & & & $\mathrm{CH}$ & \# & & \\
\hline RANGE HI & $4 \cdot 84$ & & & $\mathrm{NA}$ & & 11 I.PH & \\
\hline CAL FACTOR & $\ldots \ldots$ & & & TY & & 2 & \\
\hline STD VAL & $1 \cdot 29$ & & & $\& S$ & VOL & 14 & \\
\hline
\end{tabular}


[a]

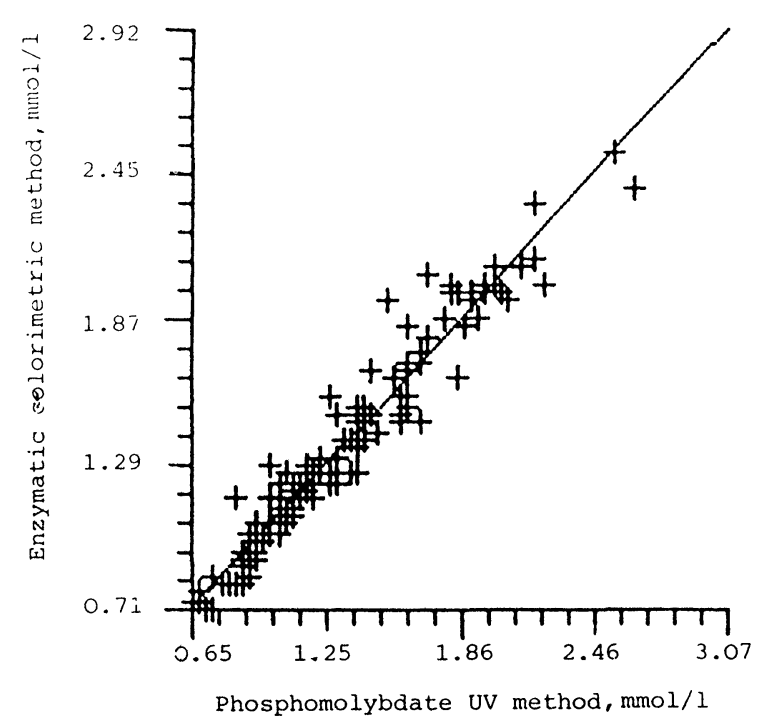

[b]

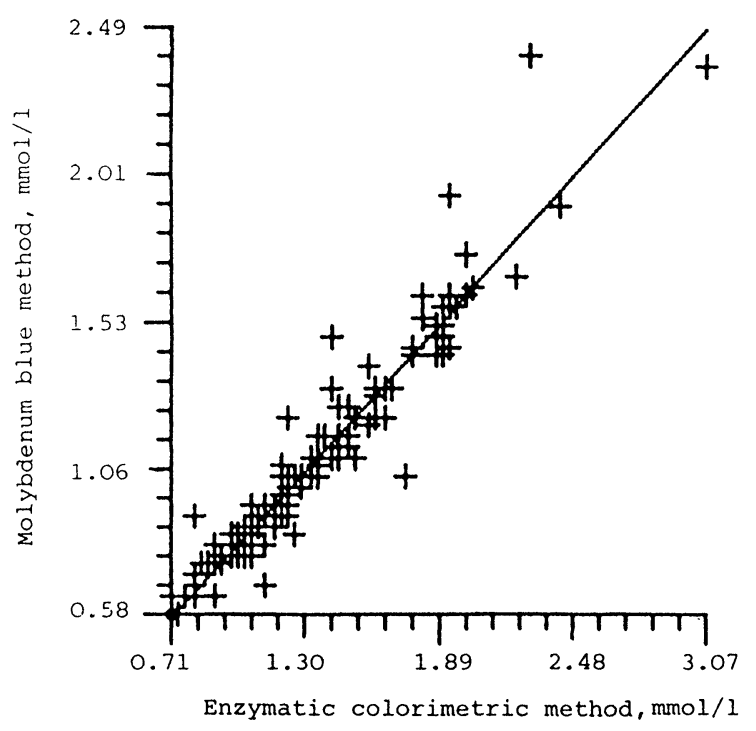

$\begin{array}{lc}\text { FILTER POS } & 6 \mathrm{WL} 600 \\ \text { DELAY } & 500 \\ \text { \% RGT VOL } & 70 \\ \text { UNITS } & 4 \mathrm{mmol} / 1 \\ \text { UNIT FAC } & 1 \cdot 0000 \\ \text { DEGIMAL PT } & 1 \\ \text { RBL LOW } & 0 \cdot 000 \\ \text { RBL HI } & 0 \cdot 250 \\ \text { RANGE LOW } & 0 \\ \text { RANGE HI } & 4 \cdot 84 \\ \text { CAL FACTOR } & \ldots \ldots \\ \text { STD VAL } & 1 \cdot 29 \\ \text { NORMAL LOW } & 0 \cdot 80 \\ \text { NORMAL HI } & 1 \cdot 55 \\ \text { SLOPE } & 1 \cdot 000 \\ \text { INTERGEPT } & 0 \cdot 0000 \\ \text { EP LIM } & 0 \cdot 0100\end{array}$

[c]

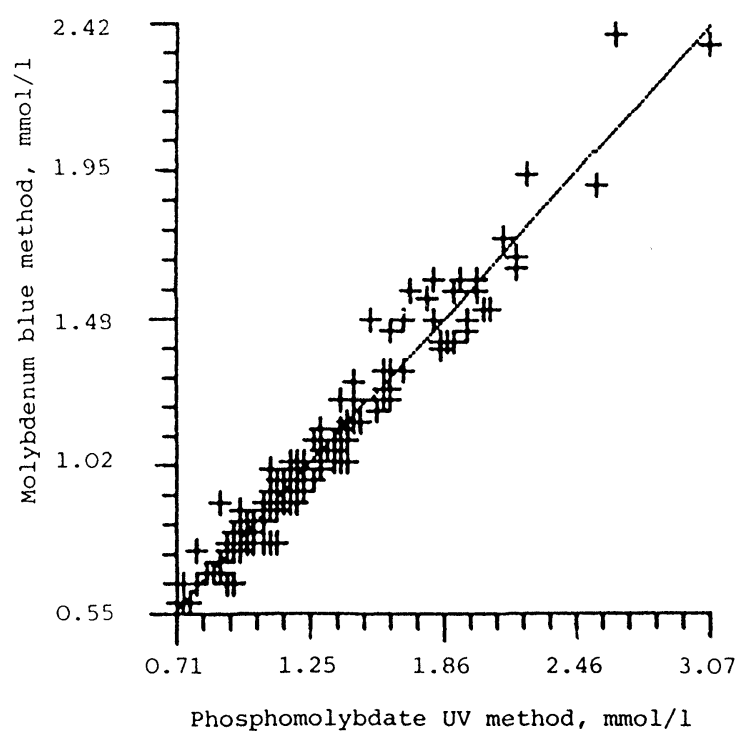

Figure 1. Correlation scattergrams and linear regression parameters for: (a) enzymatic colorimetric method $(y)$ vs phosphomolybdate UV method $(x)$, where $y=0 \cdot 898 x+$ $0 \cdot 14 ; r=0 \cdot 972 ; n=150 ;(\mathrm{b})$ molybdenum blue method $(y)$ vs enzymatic colorimetric method $(x)$, where $y=0 \cdot 808 x+$ $0 \cdot 006 ; r=0.958 ; n=150 ;$ and (c) molybdenum blue method $(y)$ vs phosphomolybdate UV method $(x)$, where $y=0.757 x$ $+0.08 ; r=0.956 ; n=150$.

\section{Results}

We determined the accuracy and precision of the assays by replicate analysis of two control sera at normal and high phosphate concentrations. These sera were determined by the three methods in 15 replicates for the within-run precision and in single over a 15-day period for the between-day precision. The data obtained were processed statistically according to Louderback and Szatkowski [13]. The coefficients of precision, accuracy and analysis are shown in table 1.

The linearity of the three methods was determined using eight aqueous phosphate solutions ranging from 0.40 $\mathrm{mmol} / \mathrm{l}$ of inorganic phosphorus. The results are given in table 2.

We explored the effect of potential interferents such as bilirubin and haemoglobin by spiking two pooled human sera at normal $(1.20 \mathrm{mmol} / \mathrm{l})$ and elevated $(2.40 \mathrm{mmol} / \mathrm{l})$ inorganic phosphorus concentrations with known amounts of these substances. No interference was found for bilirubin up to $175 \mathrm{mg} / \mathrm{l}$ with all methods and for haemoglobin up to $750 \mathrm{mg} / \mathrm{l}$ with the molybdenum blue method and up to $1000 \mathrm{mg} / \mathrm{l}$ with the other two methods.

We found for all the three methods an overestimate of inorganic phosphorus values with lipaemic samples at relatively low triglycerides concentration (about 3500 $\mathrm{mg} / \mathrm{l})$; therefore, slightly lipaemic samples should be better analyzed after a pretreatment with a clearing agent. 
Finally, we carried out a comparison study to correlate the enzymatic colorimetric method and the two chemical methods. Routine sera (150) were determined in parallel in various runs over 15 days; the samples were selected and stored at $-20^{\circ} \mathrm{C}$, and then brought to room temperature prior to determination. Results were processed by least-squares regression analysis; correlation plots and statistical parameters are shown in figure 1.

\section{Discussion and conclusions}

All three methods for determining serum inorganic phosphorus showed high precision. The enzymatic colorimetric method yielded the highest coefficients of precision both for within-run precision (99.7 and $99.5 \%$ for control sera A and B, respectively) and between-day precision ( 99.0 and $98.2 \%) ; 1-2 \%$ lower results were obtained by the UV and molybdenum blue methods.

As far as accuracy is concerned, the highest coefficient was obtained with the enzymatic colorimetric method, with the UV method yielding results slightly lower $(1-2 \%)$. Lower $(5 \%$ on average) results were obtained with the molybdenum blue method, probably because absorbance readings were not made at the peak wavelength of the molybdenum blue dye (i.e. at $600 \mathrm{~nm}$ instead of at $650-730 \mathrm{~nm}$ ) owing to the lack of the appropriate filter.

The linearity extended up to at least $4.84 \mathrm{mmol} / 1$ for both the enzymatic colorimetric method and the two chemical methods; this value is approximately four times the upper limit of the reference interval.

The linearity extended up to at least $4.84 \mathrm{mmol} / \mathrm{l}$ for both the enzymatic colorimetric method and the two chemical methods; this value is approximately four times the upper limit of the reference interval. The average recovery with respect to the standard values was $101 \cdot 1 \pm 4 \cdot 0 \%$ (SD) for the enzymatic colorimetric method, $96.9 \pm 1 \cdot 6 \%$ for the UV method and $94.4 \pm 7 \cdot 6 \%$ for the molybdenum blue method; by excluding the highest and the lowest values, the above values are $101 \cdot 2 \pm 2 \cdot 1 \%, 96 \cdot 8 \pm 1 \cdot 9 \%$, and $96 \cdot 0$ $\pm 6.9 \%$, respectively. Hence the highest correspondence between expected and found concentrations of inorganic phosphorus was found for the enzymatic colorimetric method and the lowest for the molybdenum blue method.
The correlation among methods was good $(r \geq 0.956)$. The enzymatic method and the UV method agreed very closely, giving comparable results.

In conclusion, the fully enzymatic method for serum inorganic phosphorus determination, which is based on the specific system purine nucleoside phosphorylase/ xanthine oxidase coupled to an indicator colorimetric reaction similar to the well known Trinder reaction, proved to be very precise and accurate when applied to the Technicon RA-1000 analyzer, by virtue also of the simplicity of the assay procedure. Good results were also obtained with the method based on the direct measurement of the phosphomolybdate complex in the ultraviolet region. Finally, the method involving chemical reduction of the phosphomolybdate complex to molybdenum blue showed lower performance characteristics.

\section{References}

1. Henry, J. B., Clinical Diagnosis and Management by Laboratory Methods, (W. B. Saunders, Philadelphia, 1984), p. 145.

2. Tietz, N. W., in Textbook of Clinical Chemistry, (W. B. Saunders, Philadelphia, 1986), p. 1317.

3. Shulz, D. W., Passonneau, J. V. and Lowry, O. H., Analytical Biochemistry, 19 (1967), 300.

4. Hwang, W. I. and Cha, S., Analytical Biochemistry, 55 (1973), 379.

5. Pesce, M. A., Boudourian, S. H. and Nicholson, J. F., Clinical Chemistry, 20 (1974), 332.

6. Scopes, R. K., Analytical Biochemistry, 49 (1982), 88.

7. Maghida, Y. and Nakanishi, T., Agriculture Biological Chemistry, 43 (1982), 807.

8. Ravazzani, V.,LAB, Journal of Laboratory Medicine, 4 (1986), 219.

9. Berti, G., Fossati, P., Melzi D’Eril, G. V., Tarenghi, G. and Musitelli, C., Clinical Chemistry, 33 (1987), 312.

10. Berti, G., Fossati, P., Tarenghi, G., Musitelli, G. and Melzi D'Eril, G. V., Journal of Clinical Chemistry and Clinical Biochemistry, 26 (1988), 399.

11. Daly, J. and Ertingshausen, G., Clinical Chemistry, 18 (1972), 263

12. Goldenberg, H. and Fernandez, A., Clinical Chemistry, 12 (1966), 871.

13. Louderback, A. L. and Szatkowski, P. R., Clinical Chemistry, 26 (1980), 774. 


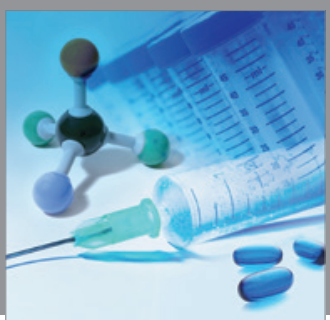

International Journal of

Medicinal Chemistry

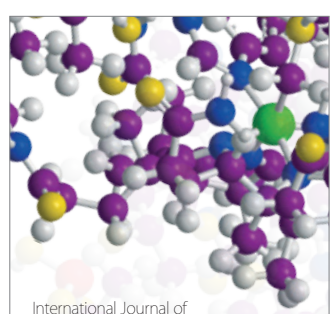

Carbohydrate Chemistry

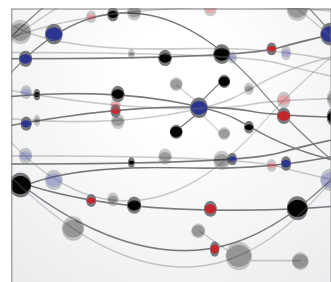

The Scientific World Journal
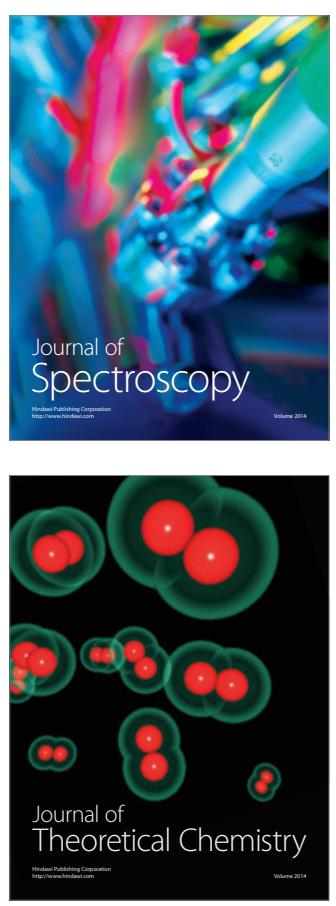
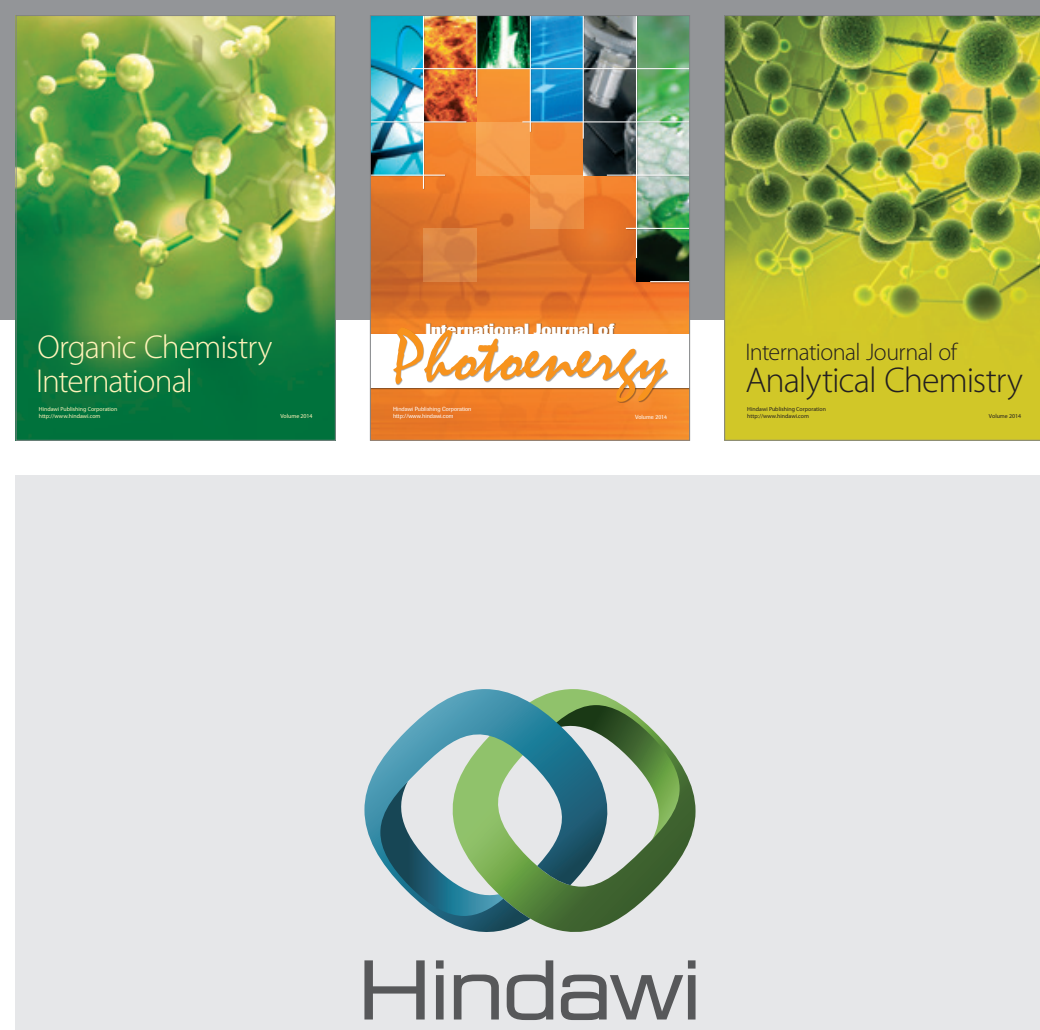

Submit your manuscripts at

http://www.hindawi.com
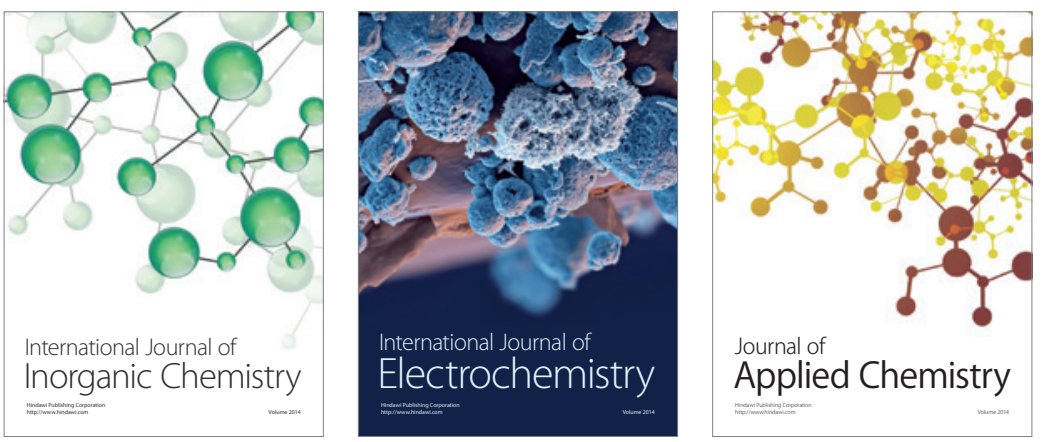

Journal of

Applied Chemistry
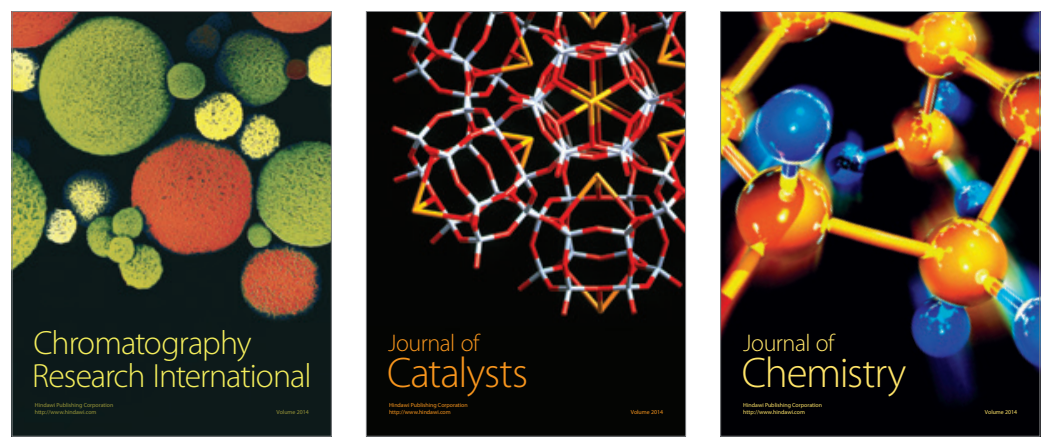
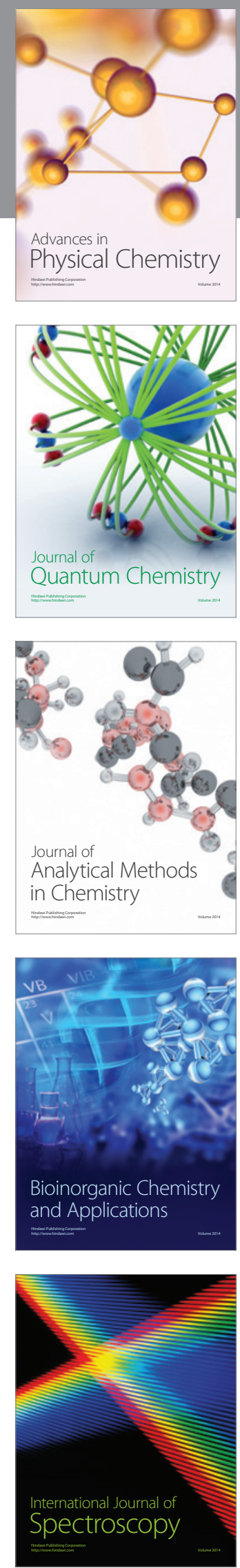